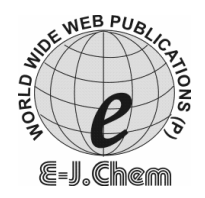

http://www.e-journals.net
ISSN: 0973-4945; CODEN ECJHAO

E-Journal of Chemistry 2009, 6(1), 273-280

\title{
Kinetics and Mechanism of the Oxidation of Lactic Acid and Mandelic Acid by Pyridinium Chlorochromate in Aqueous Acidic Medium
}

\author{
SAPANA JAIN*, B. L. HIRAN and C.V.BHATT \\ Chemical Kinetics and Polymer Research Laboratory, \\ Department of Chemistry, University College of Science, \\ Mohan Lal Sukhadia University. Udaipur-313001 (Raj.), India. \\ hiranbl@rediffmail.com
}

Received 26 June 2008; Accepted 20 August 2008

\begin{abstract}
Pyridinium chlorochromate (PCC) act as two electron oxidant in kinetic studies of the oxidation of lactic and mandelic acid in acidic medium. The influence of several factors such as acidity, salts, solvent composition and temperature on the reaction rate has been studied. The reaction shows first order dependence with respect to $[\mathrm{PCC}]$ and $\left[\mathrm{H}^{+}\right]$. The various thermodynamic parameters have been evaluated. Products as oxoacids and absence of free radical were confirmed. Suitable reaction mechanism has been proposed.
\end{abstract}

\section{Introduction}

Pyridinium Chlorochromate $(\mathrm{PCC})^{1,2}$ has been used as a mild and selective oxidizing reagent in synthetic organic chemistry. Oxidations of $\alpha$-hydroxy acid by other pyridinium and quiniolinium halochromate ${ }^{3}$, have been reported. These seem to be no report on the oxidation of $\alpha$-hydroxy acid by PCC and no report on its mechanism. Hydroxy acid may be oxidized either as alcohol, yielding corresponding oxoacids ${ }^{4}$ may undergo oxidative decarboxylation to yield a ketone ${ }^{5}$. The catalytic effect of some bidentate ligands on the oxidation of lactic acid by $\mathrm{Cr}(\mathrm{VI})^{6}$ has also been reported.

\section{Experimental}

The hydroxy acid was a commercial product of the highest purity available and used as such. PCC was prepared by reported method and its purity checked by iodometric method. Double distilled water used as a medium. The solution of perchloric acid is prepared by diluting known volume of acid in water and standardized by sodium hydroxide using phenolphthalein as an indicator. 
Product analyses were carried out under kinetic condition i.e. with an excess of the reductant over PCC. For both the acid, reaction mixture was allowed to stand in a dark for $\approx$ $24 \mathrm{~h}$ to ensure the completion of the reaction. It was then treated with an excess of a freshly prepared 2,4-dinitrophenylhydrazine (DNP). The hydroxy acids yielded the DNP of the corresponding oxoacids ( $85-91 \%$ yields) after crystallization. The oxidation state of chromium in completely reduced reaction mixture was 3 .

\section{Kinetic Experiments}

Keeping excess of the hydroxy acid over PCC attained the pseudo first order conditions. The temperature was kept constant to $\pm 0.1 \mathrm{~K}$. The reaction was followed by monitoring the optical density of the reaction mixture spectrophotometrically at $354 \mathrm{~nm}$ up to $70 \%$ of the reaction by using a digital UV/ visible spectrophotometer model. No other reactant or product had any significant absorption at this wavelength.

\section{Results and Discussion}

The rate and other experimental data were obtained for both the hydroxy acids studied and similar results were obtained. The oxidation of hydroxy acids resulted in the formation of the corresponding oxoacids. Product analysis and stoichiometric determinations indicates that the overall reaction may be written as-

$\mathrm{RCH}(\mathrm{OH}) \mathrm{COOH}+\mathrm{CrO}_{2} \mathrm{ClO}^{-} \mathrm{PyH}^{+} \longrightarrow \mathrm{RCOCOOH}+\mathrm{H}_{2} \mathrm{O}+\mathrm{CrOClO}^{-} \mathrm{PyH}^{+}$

PCC undergoes a two electron change.

\section{Effect of substrate concentration}

The reaction increases linearly with an increase in the [hydroxy acids] (Table 1). The plot of $1 / \mathrm{k}_{\text {obs }}$ versus $1 /$ [subsrate] gave linear line passing through origin suggests that the rate does not obey Michaelis-Menten type kinetics. The hydroxy acids also show first order dependence over substrate in quinolinium bromochromate $(\mathrm{QBC})^{7}$ and pyridinium hydrobromide perbromide ${ }^{8}$.

Table 1. Variation of rate with substrate concentration $[\mathrm{PCC}]=2 \times 10^{-3} \mathrm{M}$; Temp $=303 \mathrm{~K}$

\begin{tabular}{ccc}
\hline $\begin{array}{c}\text { Substrate }] \times 10^{2} \\
\mathrm{M}\end{array}$ & $\begin{array}{c}\text { Lactic acid, } \mathrm{k}_{1} \times 10^{4}, \mathrm{sec}^{-1} \\
\text { at }\left[\mathrm{H}^{+}\right]=0.5 \mathrm{M}\end{array}$ & $\begin{array}{c}\text { Mandelic acid, } \mathrm{k}_{1} \times 10^{4}, \mathrm{sec}^{-1} \\
\text { at }\left[\mathrm{H}^{+}\right]=0.2 \mathrm{M}\end{array}$ \\
\hline 1.0 & 4.03 & 4.61 \\
1.5 & 5.77 & 6.39 \\
2.0 & 7.81 & 8.27 \\
2.5 & 9.83 & 10.41 \\
3.0 & 11.44 & 12.28 \\
4.0 & 15.91 & 14.62 \\
5.0 & 20.02 & 18.35 \\
\hline
\end{tabular}

\section{Test for polymerization}

The oxidation of hydroxy acids by PCC in an atmosphere of nitrogen failed to induce the polymerization of acrylonitrile. 


\section{Effect of ionic strength}

There was no effect of $\mathrm{SO}_{4}{ }^{2-}$ and $\mathrm{CH}_{3} \mathrm{COO}^{-}$observed on the reaction rate in the Debye Huckle limit. It proves that interaction in rate determining step is not ion-ion type ${ }^{9}$ and one of the reactant molecules is neutral.

\section{Effect of solvent composition}

The rate of oxidation of lactic and mandelic acid was determined in different solvent composition [1,4-dioxane]. The kinetics is similar for both the acids in the solvent. According to Scatchard ${ }^{10}$ the plot of $\log \mathrm{k}_{\mathrm{obs}}$ versus 1/D was liner and indicates ion dipole type of interaction ${ }^{11}$ (Table 2) in rate determining step.

Table 2. Variation of rate with solvent composition.

$$
[\mathrm{PCC}]=2 \times 10^{-3} \mathrm{M} \text {; Temp }=303 \mathrm{~K} ;[\mathrm{HA}]=2 \times 10^{-2} \mathrm{M}
$$

\begin{tabular}{ccc}
\hline $\begin{array}{c}\text { Substrate }] \times 10^{2} \\
\mathrm{M}\end{array}$ & $\begin{array}{c}\text { Lactic acid } \mathrm{k}_{1} \times 10^{4}, \mathrm{sec}^{-1} \\
\text { at }\left[\mathrm{H}^{+}\right]=0.5 \mathrm{M}\end{array}$ & $\begin{array}{c}\text { Mandelic acid } \mathrm{k}_{1} \times 10^{4}, \mathrm{sec}^{-1} \\
\text { at }\left[\mathrm{H}^{+}\right]=0.2 \mathrm{M}\end{array}$ \\
\hline 0 & 7.87 & 8.27 \\
10 & 10.9 & 9.74 \\
20 & 13.12 & 13.18 \\
30 & 14.62 & 13.72 \\
40 & 19.5 & 17.42 \\
50 & 33.20 & 26.02 \\
\hline
\end{tabular}

Effect of perchloric acid

Rate of oxidation increased with increase in hydrogen ion concentration. The plot of $\log \mathrm{k}_{\mathrm{obs}}$ against $\log \left[\mathrm{H}^{+}\right]$is linear with slope for lactic acid 1.20 and mandelic acid 1.06. Therefore order with respect to $\left[\mathrm{H}^{+}\right]$ion is one. In presence of acid, PCC may be protonated. A protonated $\mathrm{Cr}(\mathrm{VI})$ species is likely to be better electrophile and oxidant compared to the neutral one (Table 3).

Table 3. Variation of rate with perchloric acid concentration

\begin{tabular}{ccc}
{$[\mathrm{PCC}]=2 \times 10^{-3} \mathrm{M} ; \mathrm{Temp}=303 \mathrm{~K} ;[\mathrm{HA}]=2 \times 10^{-2} \mathrm{M}$} \\
\hline $\left.\begin{array}{c}\text { Lactic acid } \\
\mathrm{HClO}\end{array}\right] \times 10^{1}$ & $\mathrm{k}_{1} \times 10^{4}, \mathrm{sec}^{-1}$ & $\begin{array}{c}\text { Mandelic acid } \\
\mathrm{k}_{1} \times 10^{4}, \mathrm{sec}^{-1}\end{array}$ \\
\hline 1.0 & - & 3.89 \\
2.0 & - & 8.27 \\
2.5 & 3.49 & - \\
3.0 & 4.45 & 12.13 \\
4.0 & 6.09 & 16.00 \\
5.0 & 7.87 & 21.65 \\
6.0 & 10.00 & 25.31 \\
7.0 & 12.50 & 29.90 \\
7.5 & 13.84 & 31.80 \\
9.0 & 18.51 & 40.6 \\
10.0 & 22.37 & 45.3 \\
\hline
\end{tabular}




\section{Effect of temperature}

The rate of oxidation of acids was determined at different temperature and the activiation parameters were evaluated (Table 4). Representative Figures 1-6 are given for lactic acid and similar behaviour was observed in case of mandelic acid also.

Table 4 Variation of rate with temperature

$$
[\mathrm{PCC}]=2 \times 10^{-3} \mathrm{M} ;[\mathrm{HA}]=2 \times 10^{-2} \mathrm{M}
$$

\begin{tabular}{ccc}
\hline $\begin{array}{c}\text { Temperature, } \\
\mathrm{K}\end{array}$ & $\begin{array}{c}\text { Lactic acid } \mathrm{k}_{1} \times 10^{4}, \mathrm{sec}^{-1} \\
\text { at }\left[\mathrm{H}^{+}\right]=0.5 \mathrm{M}\end{array}$ & $\begin{array}{c}\text { Mandelic acid } \mathrm{k}_{1} \times 10^{4}, \mathrm{sec}^{-1} \\
\text { at }\left[\mathrm{H}^{+}\right]=0.2 \mathrm{M}\end{array}$ \\
\hline 298 & 6.18 & 6.04 \\
303 & 7.87 & 8.27 \\
308 & 10.10 & 13.57 \\
313 & 13.61 & 16.41 \\
318 & 15.91 & 20.20 \\
323 & 20.84 & 31.91 \\
\hline
\end{tabular}

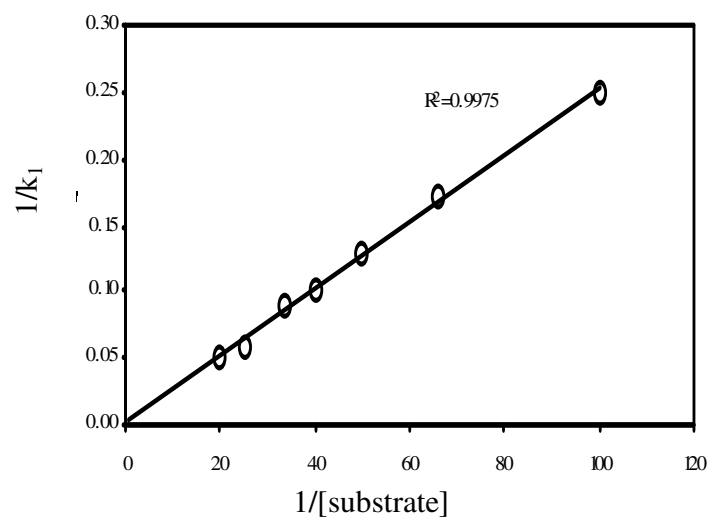

Figure 1. Variation of rate with substrate concentration.

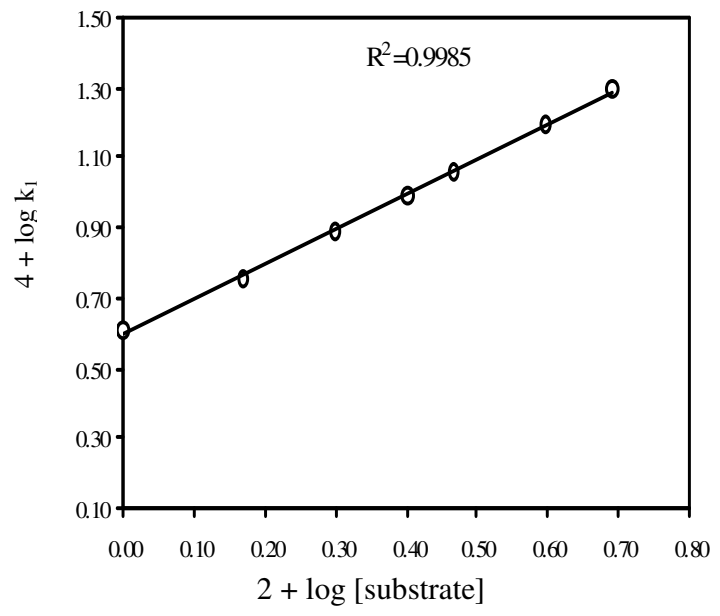

Figure 2. Variation of rate with substrate concentration. 


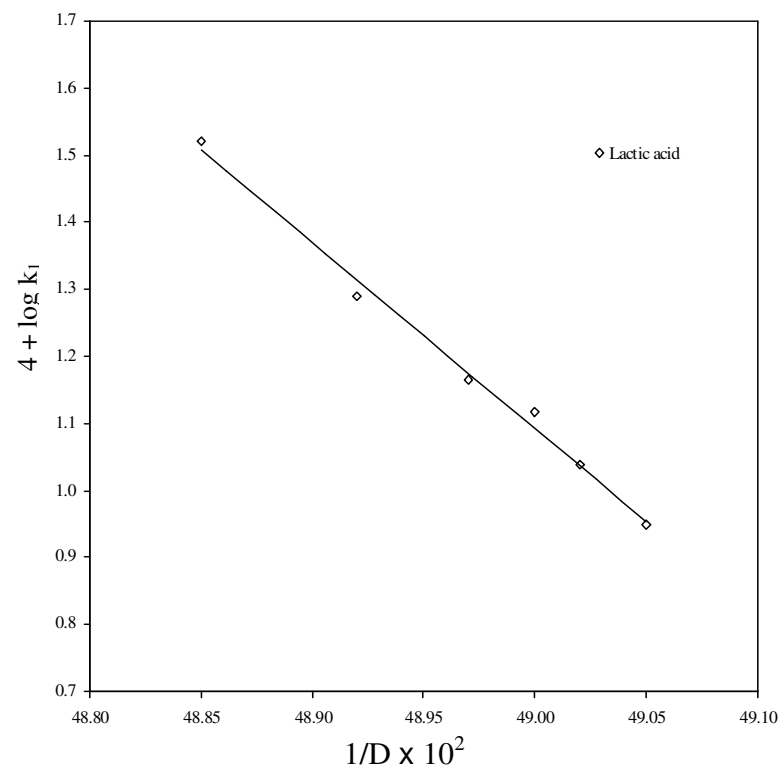

Figure 3. Variation of rate with solvent concentration (lactic acid)

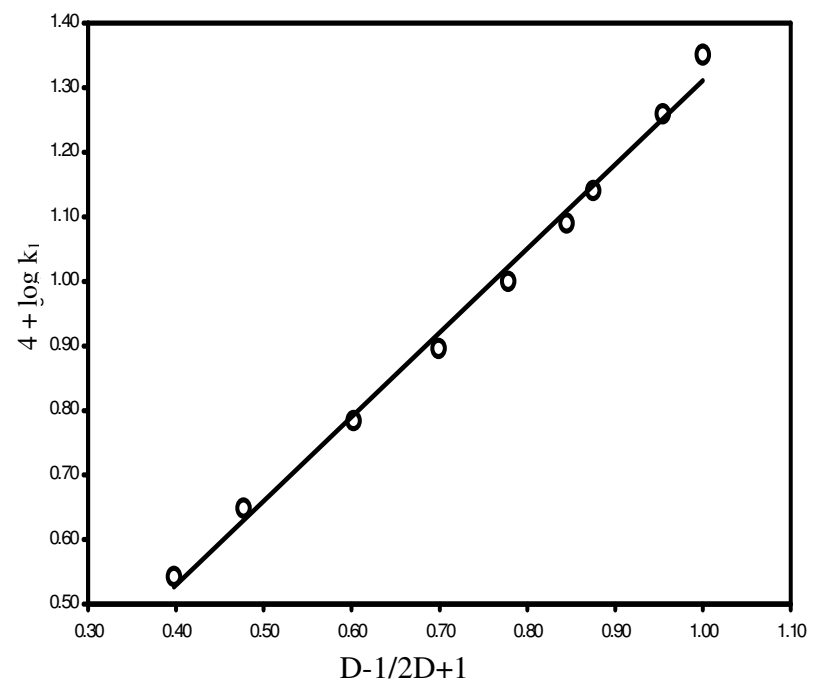

Figure 4. Variation of rate with solvent concentration

Table 5. Thermadynamic parameters for lactic acid and mandelic acid

\begin{tabular}{lcccc}
\hline Substrate & Average $\mathrm{pZ}$ & $\begin{array}{c}\text { Energy of activation } \\
\Delta \mathrm{E}_{\mathrm{a}}^{\#} \mathrm{~kJ} \mathrm{~mol}^{-1}\end{array}$ & $\begin{array}{c}\text { Entropy of activation } \\
\Delta \mathrm{S}^{\#} \mathrm{JK}^{-1} \mathrm{~mol}^{-1}\end{array}$ & $\begin{array}{c}\text { Free Energy } \\
\Delta \mathrm{F}^{\#} \mathrm{~kJ} \mathrm{~mol}^{-1}\end{array}$ \\
\hline Lactic acid & $8.876 \times 10^{6}$ & 39.164 & -96.727 & 65.952 \\
Mandelic acid & $5.451 \times 10^{10}$ & 56.406 & -24.192 & 61.2162 \\
\hline
\end{tabular}




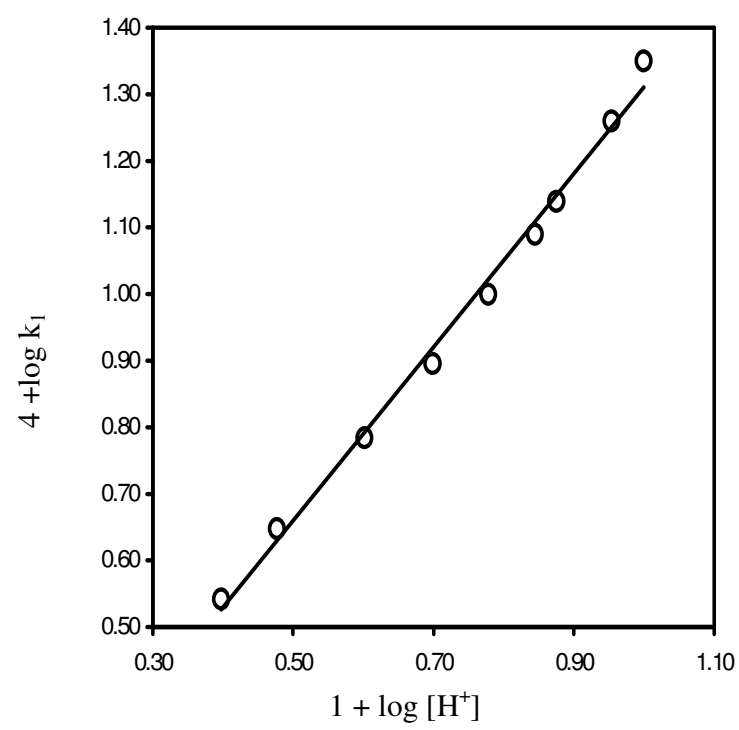

Figure 5. Variation of rate with acid concentration.

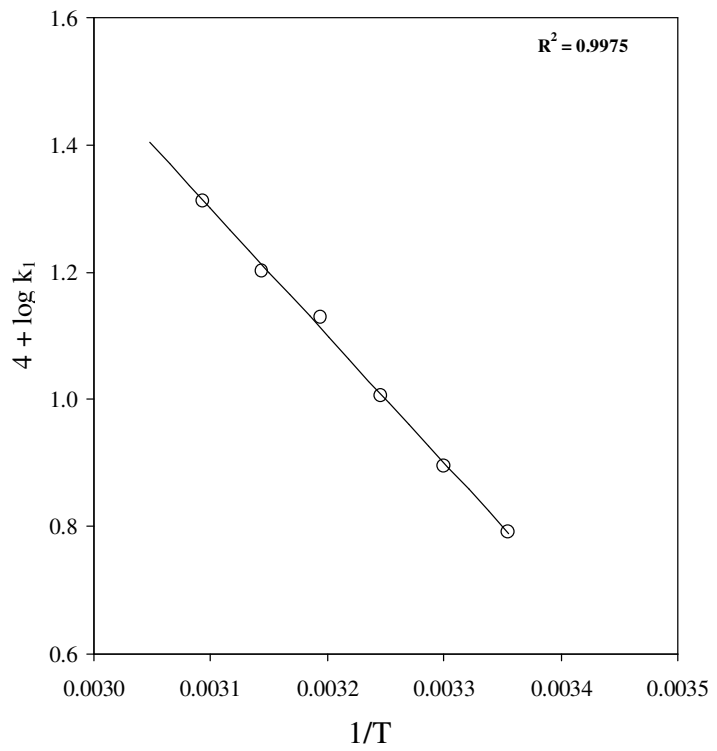

\section{Discussion}

Figure 6. Variation of rate with temperature (Lactic acid).

The rate of oxidation increased on increasing the concentration of hydroxy acid (HA). Plot of $1 / \mathrm{k}_{\mathrm{obs}}$ versus $1 /[\mathrm{HA}]$ is linear and passing through origin means no Michaelis-Menten type kinetics were observed and no reversible complex formation between acids and PCC. The rate of reaction increases with increasing $\mathrm{H}^{+}$concentration. Plot of $\log \mathrm{k}_{\mathrm{obs}} V s \log \left[\mathrm{H}^{+}\right]$is straight line with slope $\approx 1$ supports the idea that may be protonated PCC enhance the rate of oxidation. 
There is no effect of ionic strength proves that in rate determining step ions are not involved. Increase in the percentage of 1,4-dioxane increase the rate, suggest that medium of low dielectric constant favors the reaction. Linear plots of $\log \mathrm{k}_{\mathrm{obs}}$ versus $1 / \mathrm{D}$ for both the acids confirm the ion-dipole type of interaction in rate determining step. Log $\mathrm{k}$ versus $(\mathrm{D}-1) /(2 \mathrm{D}+1)$ is a straight line ${ }^{12}$, with negative slope indicates that activated state is less polar, while positive slope indicates more polar activated state. In our study we get negative slope indicate that activated state is less polar. Therefore, by increasing percentage of dioxane should increase which we have observed in both the acids. Rate of reaction increased by increasing temperature. Various thermodynamic parameters are evaluated. Energy of activation and large and negative value of entropy suggest that $\alpha-\mathrm{C}-\mathrm{H}$ bond and formation of corresponding oxoacids as product. Which fits in the criterion suggested by Narain and Bakore ${ }^{13}$. The energy of activation ranges between 37 and $57 \mathrm{~kJ} \mathrm{~mol}^{-1}$. Energy of activation does not correspond to carbon-carbon bond fission in the decomposition of organic substrates by $\mathrm{Cr}(\mathrm{VI})$ in rate-determining step. Calculation of activation parameters showed that these reactions are not enthalpy controlled. Lowest energy of activation is not associated with highest rate or vice versa. Vazirani et al ${ }^{14}$ also observed similar value of energy of activation for chronic acid oxidation of mandelic acid.

The observed negative value of entropy of activation also supports it. As the charge separation takes place, the charged ends become highly solvated. This results in an immobilization of a large number of solvent molecules, reflected in less of entropy ${ }^{15}$.

It is of interest to compare the mode of oxidation of hydroxy acids by $\mathrm{QBC}^{7}, \mathrm{PFC}^{3}$ and PCC. The oxidation by PFC exhibited Michaelis-Menten type kinetics with respect to hydroxy acids. While the oxidation by PCC and QBC present a similar kinetic picture. The rate laws and hydrogen ion dependence are similar in both the cases.

According to above data, suitable mechanism is proposed as follows -
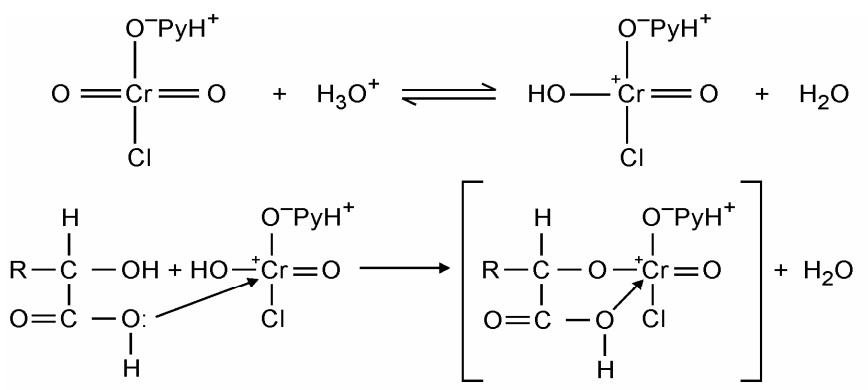

$\mathrm{R}=\mathrm{CH}_{3}-[$ Lactic acid $]$

$\mathrm{R}=\mathrm{C}_{6} \mathrm{H}_{5}-$ [Mandelic acid]

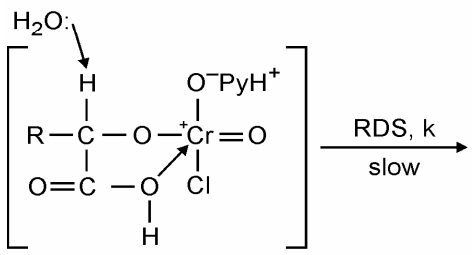

$\mathrm{R}-\underset{\mathrm{C}}{\mathrm{C}}=\mathrm{O}+\mathrm{Cr}(\mathrm{IV})+\mathrm{H}_{3} \mathrm{O}^{+}$
$\mathrm{O}=\mathrm{C}-\mathrm{OH}$ 


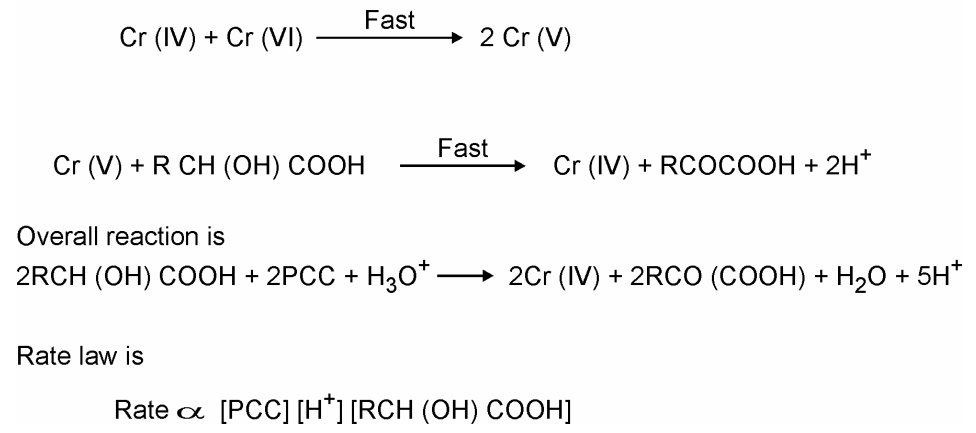

\section{References}

1. Corey E J and Suggs W J, Tetrahedron Lett., 1975, 2647.

2. Pandurangan A, Murugesan V and Palanichamy M, J Indian Chem Soc., 1995, 72, 479.

3. Asopa R, Agrawal S, and Banerji K K, Proc Indian Acad Sci., (Chem Sci.,) 1991, 104, 563.

4. Banerji. K K, J Chem Res (S), 1978, 193.

5. Levesley P and Waters W A, J Chem Soc., 1995, 215.

6. Hiran B L and Chaturvedi G, J Indian Chem Soc., 2004, 84, 556.

7. Saraswat S, Sharma V and Banerji K K, J Indian Chem Soc., 2002, 79, 871.

8. Aparna P, Kothari S and Banerji K K, Indian J Chem., 1993, 32(A), 1086.

9. Glasstone S, Laidler K J and Eyring H, Theory of Rate Proces. McGraw-Hill, New York, 1941.

10. (a) Scatchard G, J Chem Phys., 1939, 7, 657; (b) Scatchard G, Chem Rev., 1932, 10, 229.

11. Amis E S, Solvent effect on reaction rates and mechanism, Academic press, New York, 1966, 45.

12. Laidler K J and Eyring H, Ann N Y Acad Sci., 1940, 39, 303.

13. Baroke G V and Narain S, Z Physik Chem., (Leipzig), 1964, 8, 227.

14. Vazirani S, Ph.D. Thesis, Kinetics of oxidation of some esters of $\alpha$-hydroxy acids by ions of transition metal. M.L.S., University (Udaipur), 1986.

15. Gould E S, Mechanism and structure in organic chemistry, Holt, Rinehart \& Winston Inc., New York 1964, 181. 


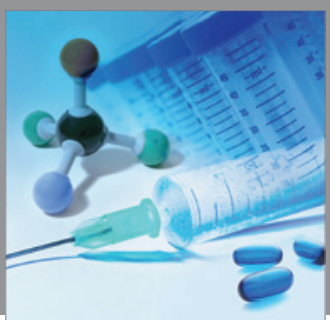

International Journal of

Medicinal Chemistry

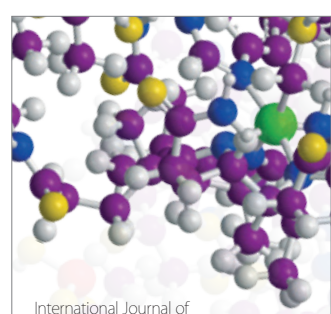

Carbohydrate Chemistry

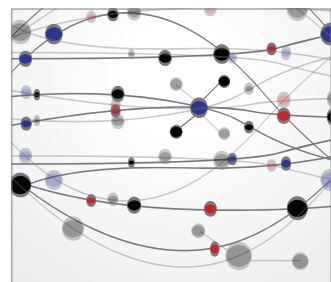

The Scientific World Journal
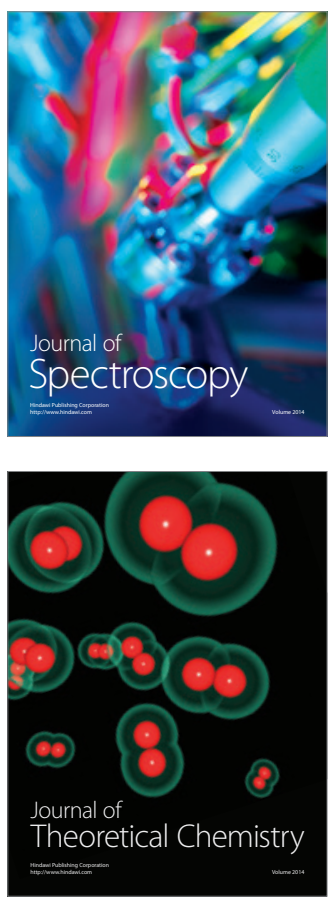
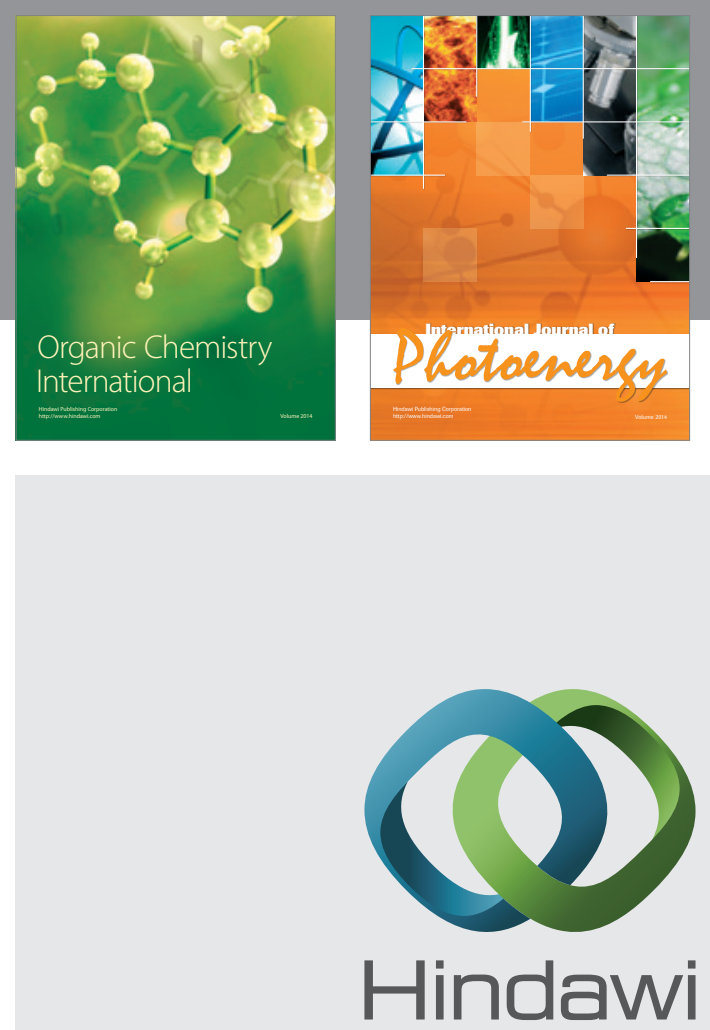

Submit your manuscripts at

http://www.hindawi.com
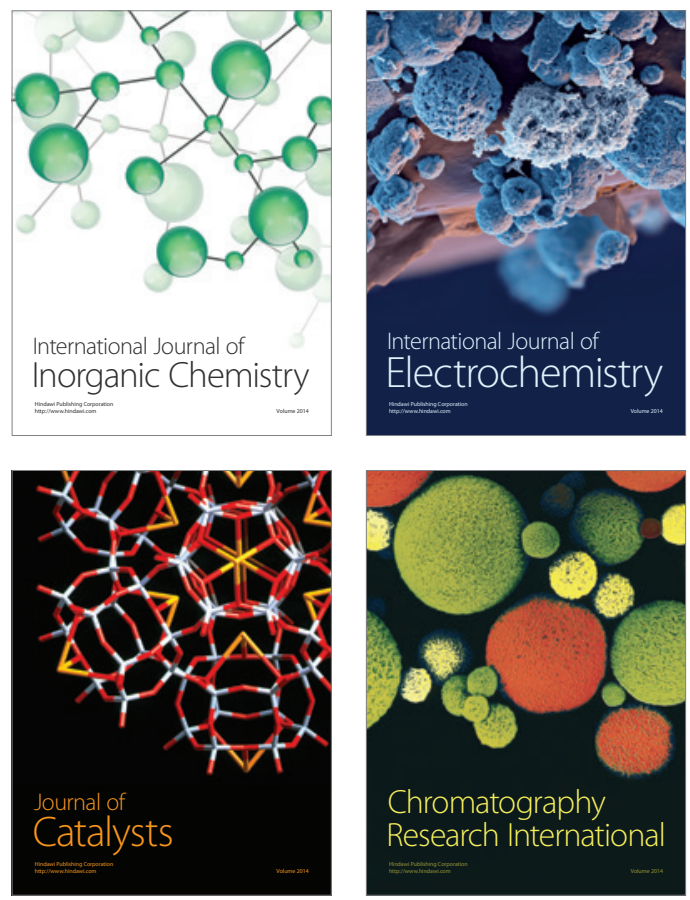
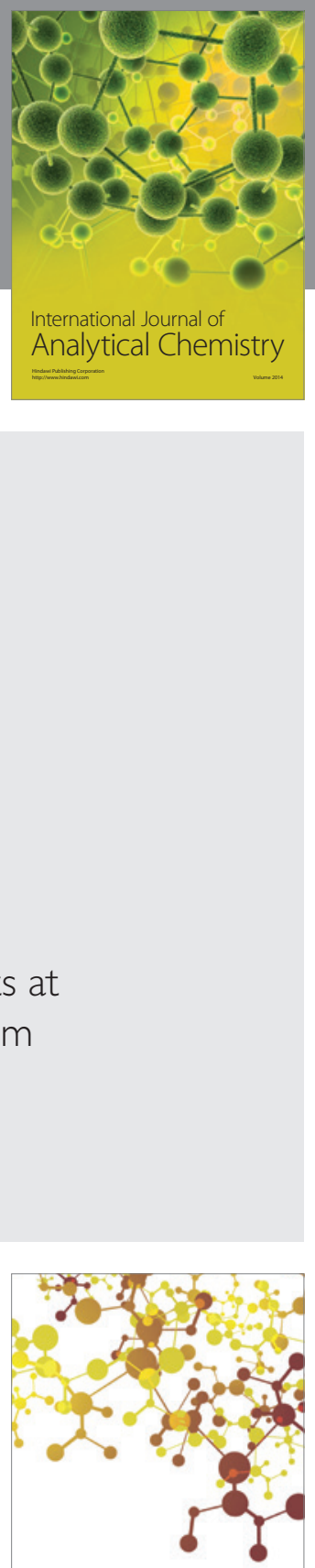

Journal of

Applied Chemistry
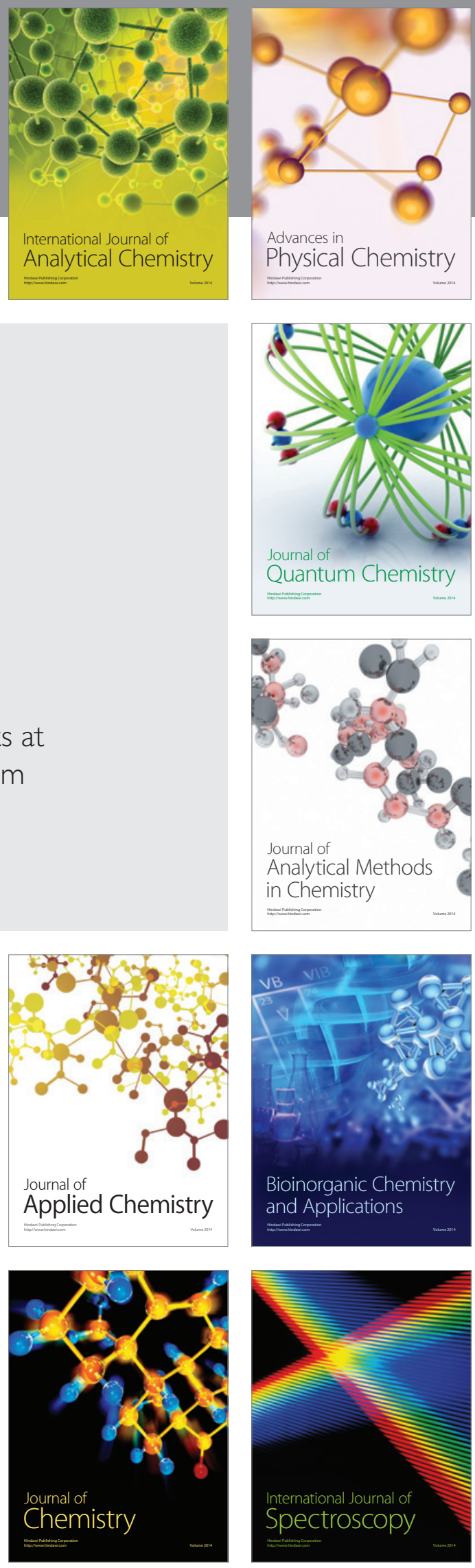